\title{
Sosialisasi Pembuatan Briket Sampah Organik Rumah Tangga Sebagai Sumber Energi Alternatif
}

\section{Article History: \\ Received: Oktober \\ 2021 \\ Revised:November 2021 \\ Accepted:November 2021 \\ Available online: \\ Desember 2021}

Irnanda Priyadi ${ }^{1}$, Faisal Hadi ${ }^{2}$, Alex Surapati ${ }^{3}$

${ }^{123}$ Teknik Elektro, Universitas Bengkulu e-mail : irnanda_p@unib.ac.id

\section{Keywords:}

Briket, Sampah Organik, Sumber Energi Alternatif, Sosialisasi,Pengolahan Sampah.

$\begin{array}{lcr}\text { Abstract: } & \text { Wabah pandemi } & \text { korona } \\ \text { menimbulkan } & \text { implikasi yang } & \text { cukup }\end{array}$
signifikan hampir di semua sektor kehidupan. Banyak masyarakat yang terpaksa kehilangan pekerjaan. Hal ini mengakibatkan daya beli masyarakat terutama terkait dengan sumber energi penggerak ekonomi keluarga menjadi berkurang. Untuk itu perlu membekali masyarakat dengan keterampilan yang bisa menunjang aktifitas ekonomi keluarga dengan biaya murah. Di sisi lain, hampir setiap rumah tangga baik yang ada di kota maupun pelosok desa memproduksi sampah setiap harinya. Namun keberadaan sampah rumah tangga sering tidak termanfaatkan secara optimal di tengah masyarakat, khususnya sampah organik rumah tangga. Artikel ini membahas bagaimana mengolah sampah organik rumah tangga agar bisa menjadi lebih bermanfaat. Metode yang digunakan dengan memberikan sosialisasi pengolahan sampah untuk bahan baku briket. Dalam laporan ini, produk briket yang dihasilkan berasal dari ranting pohon atau daunan kering yang jatuh berserakan di halaman rumah warga. Dari olahan sampah ini dapat menghasilkan briket biomassa yang bisa digunakan sebagai sumber energi alternatif di rumah tangga. Briket yang dihasilkan bisa digunakan untuk memanggang ikan, dan lama waktu pemanggangan mencapai kisaran 4 - 7 menit. 


\section{Pendahuluan}

Warga RT 17 RW 06 yang beralamat di jalan Halmahera Perumahan Permata Griya Asri Kelurahan Surabaya Kecamatan Sungai Serut Kota Bengkulu memiliki jumlah kepala keluarga hampir mencapai 100 kk. Mayoritas pekerjaan warga RT 17 adalah pegawai negeri sipil, polisi dan tentara. Sekitar 5 persennya berprofesi sebagai pedagang, pensiunan dan swasta. Prestasi yang pernah di raih RT 17 di tingkat kota antara lain pernah mewakili Kelurahan Surabaya Kota Bengkulu dalam program Bengkulu Bisa Tahun 2019. Acara yang di adakan oleh Pemerintah Kota Bengkulu, berhasil membawa RT 17 meraih juaran harapan 4, meskipun untuk kegiatan yang serupa di tahun 2018 RT 17 pernah meraih juara ketiga. RT 17 juga pernah meraih juara ke tiga pada lomba Bengkulu Menyala yang disponsori oleh PT. PLN kota Bengkulu pada tahun 2019.

Keikutsertaan RT 17 pada beberapa lomba kebersihan tingkat kota menunjukkan antusiasme yang tinggi dari warga untuk selalu menjaga kondisi lingkungan yang asri. Gambaran situasi perumahan warga RT 17 terlihat asri karena dipenuhi pepohonan yang tumbuh hampir di setiap rumah warga. Selain itu disebagian jalan dalam perumahan juga ditanami pohon yang berasal dari swadaya warga dan bantuan pemerintah kota. Kepedulian warga terhadap kebersihan lingkungan juga ditunjukkan dengan program gotong royong yang diadakan rutin setiap periode tertentu. Termasuk usaha warga untuk mengatasi persoalan sampah rumah tangga.

Sampah rumah tangga yang paling banyak dijumpai di lingkungan perumahan Permata Griya Asri adalah jenis sampah organik yang dihasilkan dari pohon dan tanaman yang ada di sekitar perumahan. Sampah organik yang berupa kayu, daun dan ranting yang berserakan hampir disepanjang perumahan sebagian dibuang ke masing-masing tempat sampah warga untuk kemudian diangkut oleh petugas kebersihan yang dikelola oleh pihak swasta untuk dibawa ke Tempat Pembuangan Akhir (TPA) Air Sebakul. Dan sebagian lagi dari sampah yang berserakan disepanjang jalan dan pekarangan rumah warga dikumpulkan untuk dibakar oleh sebagian warga.

Artikel ini akan membahas bagaimana mengolah sampah organik rumah tangga menjadi produk yang lebih berdaya guna. Melalui kegiatan 
sosialiasi, sampah organik rumah tangga yang berasal dari pohon dan tanaman akan diolah menjadi produk briket sebagai sumber energi alternatif bagi warga. Produk briket yang dihasilkan mengandung energi biomassa sebagai sumber energi alternatif pengganti bahan bakar fosil karena beberapa sifatnya yang menguntungkan, yaitu dapat dimanfaatkan secara lestari karena sifatnya yang dapat diperbarui (renewable resources), sumber energi ini relatif tidak mengandung unsur sulfur sehingga tidak menyebabkan polusi udara, dan juga dapat meningkatkan efisiensi pemanfaatan sumber daya hutan. Biomassa meliputi limbah kayu, seperti limbah dari hasil pertanian, perkebunan, hutan, serta komponen organik dari industri dan rumah tangga. Teknologi yang digunakan untuk mengkonversi biomassa menjadi bahan bakar padat, cair, dan gas, antara lain teknologi briquetting (briket), pirolisa (bio-oil), esterifikasi (bio-diesel), teknologi fermentasi (bio-etanol), anaerobik digester (biogas). (Saputro, 2012)

Kerapatan (densitas) material penyusun briket dapat dihitung dengan membandingkan massa dan volume briket. Hasil penelitian Setiowati tentang pengaruh tekanan (pengepresan) dan komposisi bahan terhadap sifat fisis briket arang diketahui bahwa nilai densitas terendah sebesar 0,455 (gr/ $\left./ \mathrm{cm}^{3}\right)$ pada komposisi bahan didapatkan hasil bahwa $100 \%$ serbuk kayu menggunakan tekanan $50\left(\mathrm{~N} / \mathrm{cm}^{2}\right)$, sedangkan nilai densitas optimum yaitu $0,652\left(\mathrm{gr} / \mathrm{cm}^{3}\right)$ pada komposisi bahan $100 \%$ tempurung kelapa menggunakan

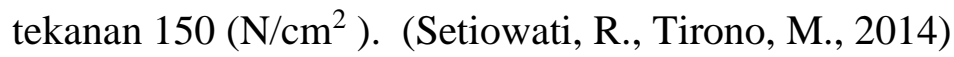

Briyartendra dkk (2019), melakukan penelitian untuk mengetahui pengaruh ukuran partikel dan tekanan kompaksi terhadap karakteristik fisik, mekanik dan thermal briket serbuk kayu jati tanpa perekat dan dengan perekat tepung kanji. Pembriketan dilakukan menggunakan kompaksi cetakan dan perekat kanji. Cetakan logam ukuran diameter luar $60 \mathrm{~mm}$, diameter dalam 25 $\mathrm{mm}$, dan tinggi $120 \mathrm{~mm}$. Perekat briket dengan menggunakan kanji dengan perbandingan 1:10. Pengompaksian menggunakan pompa hidrolik. Setelah dikompaksi briket dikeluarkan dari cetakannya lalu dioven dengan waktu 2 jam dalam suhu $100^{\circ} \mathrm{C}$ untuk mengeringkan dan menghilang-kan kadar air akibat campuran lem. 
Hasil penelitian menunjukan kadar air pada briket setelah diberikan penambahan perekat kanji naik hingga $82,75 \%$, kadar abu dan kadar zat terbang tetapi tidak terlalu signifkan hanya $7,13 \%$ dan $2,58 \%$. Nilai kalor dan kadar carbon mengalami penurunan yang sangat signifikan dengan adanya penambahan briket yang mencapai hingga $54,07 \%$ dan $38,51 \%$. Sedangkan variasi tekanan dan mesh mempengaruhi terhadap sifat fisik sifat mekanis dan sifat thermal briket. (Briyartendra, E.I., Widayat, W., 2019)

Indriawan dkk (2020), meneliti pengaruh ukuran mesh, tar dan tekanan kompaksi terhadap karakteristik briket. Hasil pengujian drop test terkecil didapatkan pada ukuran mesh 100, tar 8\%, dan tekanan kompaksi $100 \mathrm{MPa}$ dengan nilai $0,42 \%$. Sedangkan pengujian densitas terbesar didapatkan pada ukuran mesh 100, tar 0\% dan tekanan kompaksi $100 \mathrm{MPa}$ dengan nilai 0,000965 g/cm ${ }^{3}\left(964,661 \mathrm{Kg} / \mathrm{m}^{3}\right)$. (Indriawan, dkk, 2020)

\section{Metode}

Metode pendekatan yang ditawarkan untuk mendukung realisasi kegiatan ini adalah sebagai berikut :

Langkah pertama dalam kegiatan ini adalah penyiapan dan pengumpulan bahan baku. Bahan baku yang di kumpulkan adalah sampah daun-daunan dan ranting pohon disekitar perumahan warga RT 17. Sampah kemudian di keringkan sehingga mempunyai kadar air sekitar $10 \%$ dan dihaluskan. Tahap selanjutnya membuat mesin pencetak briket dengan desain sebagai berikut (Riyadi, dkk, 2016)
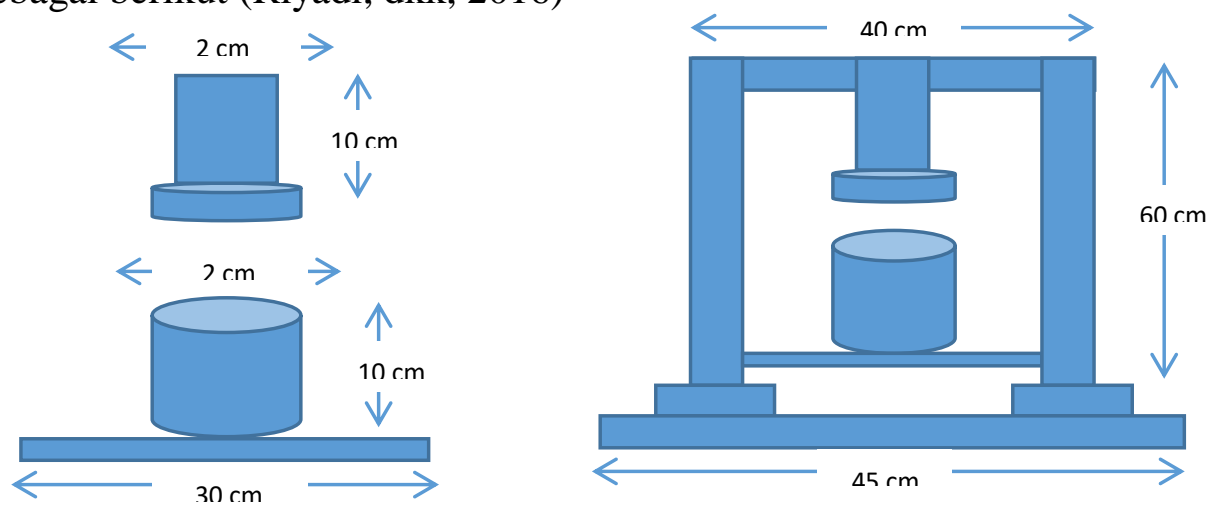

Gambar 1. Desain Mesin Pencetak Briket 
Setelah itu dilakukan peninjauan terkait hubungan antara tekanan kompaksi (tekanan yang diberikan pada cetakan briket) dan densitas dalam kegiatan sosialisasi ini sebagai berikut. Tekanan kompaksi yang dipakai sebesar 3000 Psig s.d 7000 Psig. Densitas briket naik seiring dengan naiknya tekanan kompaksi. Densitas dipengaruhi oleh kadar air briket, dalam penelitian ini kadar air seragam pada setiap variasi tekanan kompaksi, diharapkan dengan kadar air yang tetap memberikan hasil analisis densitas lebih akurat. Densitas menentukan kualitas briket, angka yang tinggi menunjukkan kekompakan briket. Densitas yang dihasilkan dalam penelitian ini berkisar antara $0.8721 \mathrm{gr} / \mathrm{cm} 3$ sampai dengan $1,0127 \mathrm{gr} / \mathrm{cm} 3$, nilai densitas tertinggi dihasilkan pada tekanan kompaksi 7000 Psig. (Riyadi, dkk, 2016)

Berikutnya hasil penelitian Santosa dan Soemarno dapat diketahui bahwa nilai kalor sampah tergantung dari kandungan kadar air dalam sampah. Sisa makanan mempunyai nilai kalor 5875,5689 kal/gr, sampah daun 5334,4857 kal/gr, sampah kayu/ranting 5975,5871 kal/gr, persentase kadar air tertinggi adalah sampah kayu/ranting sekitar 13,7495\% dari total volume sampah yang ada di TPA. Nilai kalor sampah organik dapat ditingkatkan melaui proses Bio-drying, yaitu pengelolaan fraksi organik sampah padat perkotaan dan rumah tangga untuk mengurangi kadar air sehingga dapat dijadikan untuk recovery energi karena memungkinkan dilakukannya produksi energi. (Santosa, S., Soemarno, 2014)

Selanjutnya dilakukan juga penelitian tentang karakteristik dan pengaruh jenis bahan baku dan persentase perekat yang berbeda terhadap mutu briket biomassa yang dihasilkan dan menentukan perlakuan manakah yang memberikan hasil terbaik terhadap karakteristik briket yang dihasilkan.

Parameter penelitian yang diamati adalah kadar air, kadar abu, kadar zat menguap dan laju pembakaran. Seluruh perlakuan diulang sebanyak 3 kali ulangan sehingga didapatkan 27 unit percobaan. Data yang diperoleh dianalisis dengan sidik ragam dan apabila terdapat pengaruh perlakuan yang signifikan, maka dilanjutkan dengan uji Duncan Multiple Test (DMRT).

Berdasarakan hasil penelitian sebelumnya diketahui bahwa, interaksi perlakuan memberikan pengaruh yang signifikan terhadap parameter kadar air, kadar abu, kadar zat menguap dan laju pembakaran. Selanjutnya Kadar air 
yang didapat berkisar antar 2,30\% bb - 4,78\%bb kadar abu 5,88\% - 34,85\%, kadar zat menguap 31,30\% - 51,59\% dan laju pembakaran 73,20 gr/menit $106,00 \mathrm{gr} / \mathrm{menit}$. Kualitas briket yang paling baik diperoleh pada perlakuan A2B3 (arang sekam 80 gram perekat 20 gram) dimana kadar air yang dihasilkan sebesar 2,30\%bb, kadar abu 32,29\%, kadar zat menguap 32,01\% dan laju pembakarannya 92,60 gr/menit. (Wijaya, A.A., dkk, 2021)

Secara umum bahan bakar padat yang baik mempunyai kandungan karbon yang tinggi, dengan harapan nilai kalor yang dihasilkan semakin tinggi pula. Besarnya tekanan kompakasi tidak berpengaruh terhadap nilai kalor, tetapi berpengaruh terhadap kandungan energy density. Kandungan energy density akan bertambah seiring dengan bertambahnya tekanan kompaksi, sehingga semakin tinggi tekanan kompaksi akan menaikan energy density pada briket.

Tahapan berikutnya sosialisasi materi tentang gambaran umum persoalan sampah, kategori sampah, beberapa metode pengolahan sampah di negara maju, pengenalan teknologi pengolah sampah, pengenalan briket, jenis dan macam briket, briket sampah organik, proses pengolahan sampah menjadi briket. Selanjutnya metode dilanjutkan dengan melakukan praktik langsung (demo) mengolah sampah menjadi briket mengikuti panduan-panduan yang telah disampaikan saat presentasi materi. Pemilihan metode pelaksanaan sosialisasi dengan cara penyampaian materi dan demonstrasi didasari atas kondisi tingkat pendidikan dan tingkat pemahaman warga yang tidak sama. Selain itu, penyampaian materi dan demonstrasi memiliki manfaat psikologis bagi peserta yang hadir antara lain perhatian warga menjadi lebih terfokus, proses transfer ilmu lebih terarah pada materi yang diberikan dan pengalaman dan kesan yang lebih melekat pada peserta saat mengikuti materi dilanjutkan dengan demonstrasi. (Riadi, 2012)

Evaluasi kegiatan pelaksanaan pengabdian dilakukan untuk melihat sejauh mana keberlanjutan kegiatan ini berjalan. Partisipasi semua warga RT 17 dan pejabat setempat dalam hal ini sangat besar peranannya untuk kesuksesan kegiatan pengabdian yang dilakukan. Terutama keberlanjutan program pengelolaan sampah rumah tangga di lingkungan Perumahan Permata Griya Asri RT 17 RW 06 Kelurahan Surabaya Kota Bengkulu. Secara 
umum, salah satu bentuk indikator keberhasilan program pengabdian ini antara lain misalnya beberapa anggota keluarga di lingkungan RT 17 yang telah terlatih dalam pengolahan sampah organik menjadi briket diharapkan mampu diterapkan pada warga RT yang lain di lingkungan RW 06 Perumahan Permata Griya Asri serta mampu memberikan transfer ilmu pengetahuan pada anggota-anggota keluarga di lingkungan sekitar sehingga keberlanjutan program akan tetap terjaga.

\section{Hasil}

Setelah melakukan perancangan desain mesin pencetak briket, selanjutnya dilakukan pengerjaan (eksekusi) terhadap rancangan yang telah dibuat. Berikut tahapan dan dokumentasi pengerjaan mesin pencetak briket, mulai dari menyiapkan bahan (Gambar 2), membuat cetakan briket (Gambar 3), dilanjutkan dengan membuat tiang penyangga (Gambar 4) dan stick pendorong cetakan briket (Gambar 5).

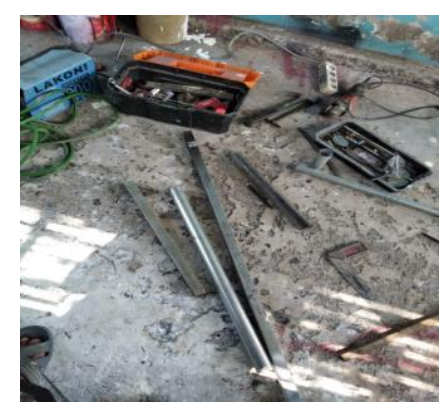

Gambar 2a. Menyiapkan Bahan



Gambar 2c.Tiang Penyangga

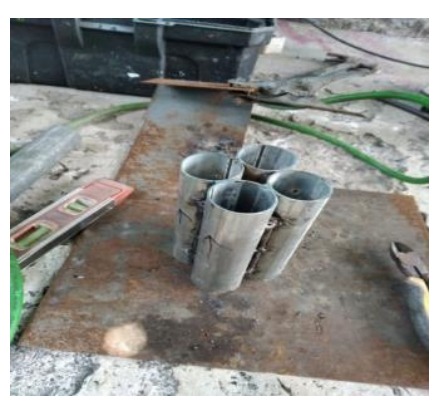

Gambar 2b. Cetakan Briket

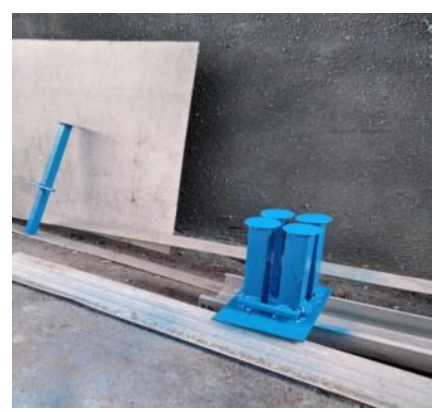

Gambar 2d. Stick 
Bahan yang digunakan untuk membuat mesin pencetak briket menggunakan besi pipa berdiameter 1,5 inch dengan tinggi tabung cetakan 14 $\mathrm{cm}$. Untuk tiang penyangga memiliki dimensi tinggi $60 \mathrm{~cm}$, panjang $40 \mathrm{~cm}$ dan lebar $30 \mathrm{~cm}$. Prinsip kerja mesin pencetak briket menggunakan alat bantu tekan (press) agar briket yang dihasilkan lebih padat. Dalam hal ini alat bantu tekan menggunakan dongkrak hidrolik kapasitas beban 1,5 ton (Gambar 6). Ukuran briket yang dihasilkan setelah di-press menggunakan alat bantu dongkrak hidrolik sekitar $8 \mathrm{~cm}$ (Gambar 7).

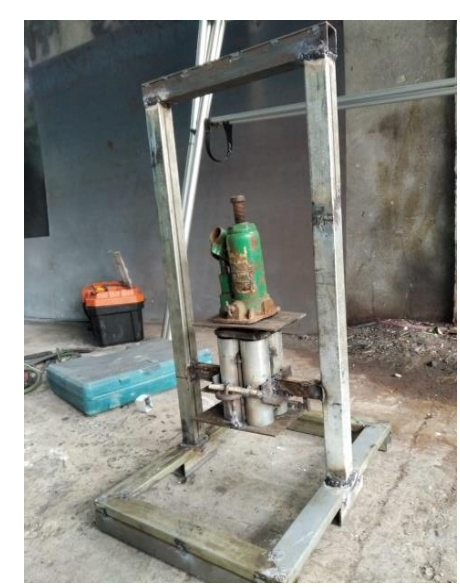

Gambar 3a. Alat Bantu Tekan

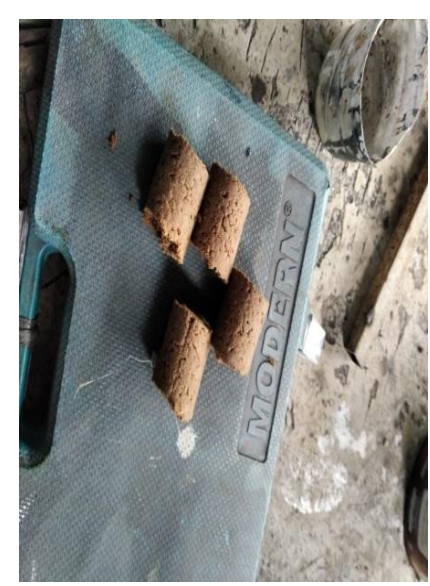

Gambar 3b. Briket yang Dihasilkan

Pekerjaan selanjutnya yang dilakukan adalah membuat kompor pembakar sampah sebagai bahan baku briket. Dalam hal ini sampah rencananya akan dibakar langsung didalam bak sampah. Agar tempat pembakar sampah bisa lebih fleksibel (bisa dibawa) maka dibuat juga kompor pembakar sampah sederhana memanfaatkan barang bekas berupa ember cat kaleng yang disusun dua tingkat. Gambar 8 dan Gambar 9 merupakan dokumentasi tahapan pembuatan kompor. 

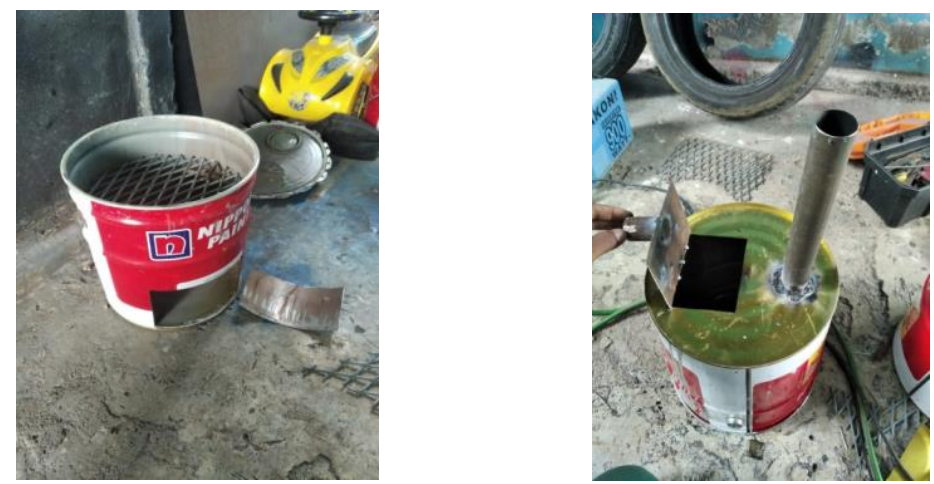

Gambar 3a. Penyaring Sampah Gambar 3b. Katup dan Cerobong Berikut hasil akhir kompor pembakar sampah, serta bahan dan alat yang dibutuhkan untuk membuat briket biomassa.
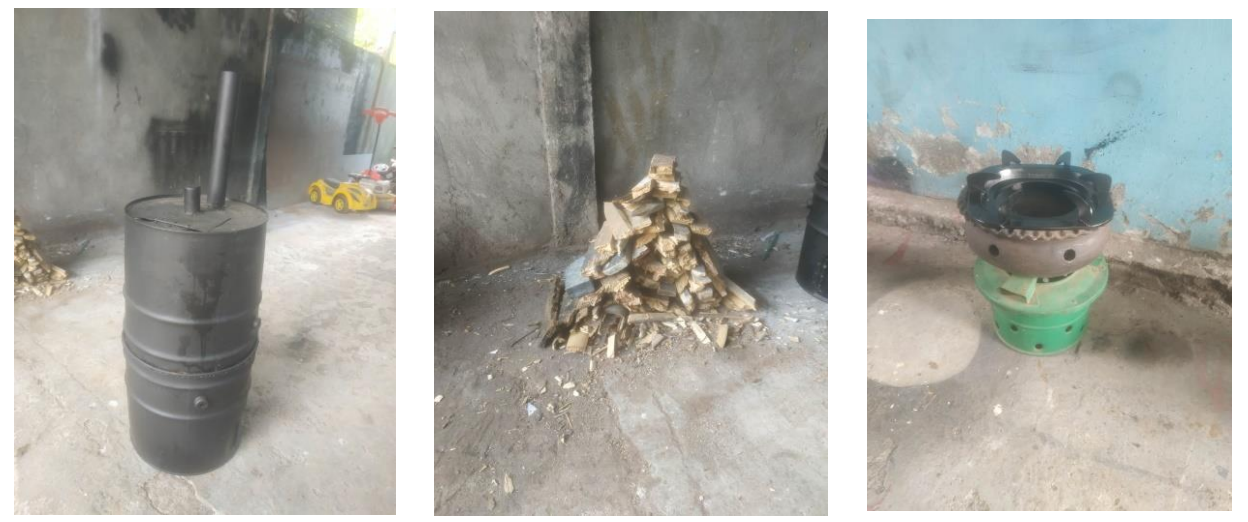

Gambar 4. Kompor Pembakar Sampah (4a,)

-. Sampah Organik Kering (4b)

-. Tungku Kompor Briket (4c)

\section{Diskusi}

Diskusi tentang kegiatan pengabdian mengarah ke pengembangan alat dan produk yang dihasilkan. Terkait dengan pengembangan alat muncul ide untuk mencoba mencari sumber bahan baku alternatif untuk membuat briket, diantaranya kertas bekas dan plastik bekas dari sampah rumah tangga. (Ilyas, 2016) (Septhiani, 2015). 
Sedangkan terkait produk briket muncul ide untuk mengembangkan briket sampah organik sebagai sumber bahan baku pembangkit listrik. Dari referensi publikasi jurnal berjudul Simulasi Pembuatan Dan Pemanfaatan Briket Pada Listrik Kerakyatan yang terbit pada Jurnal PETIR Vol. 11 No. 1 Maret 2018 dapat diketahui bahwa briket yang berasal dari bahan sampah organik dan non organik sebagai sumber bahan bakar alternatif memiliki potensi untuk dikembangkan menjadi bahan baku sumber pembangkit listrik tenaga gas. (Sikumbang, 2018)

\section{Kesimpulan}

1. Briket biomassa dari sampah organik rumah tangga yang dihasilkan dapat digunakan sebagai sumber energi di rumah tangga, antara lain memanggang ikan / ayam untuk makanan lauk pauk di rumah tangga.

2. Kisaran lama waktu yang dibutuhkan untuk memanggang ikan menggunakan briket biomassa yang dihasilkan antara 4 sampai 7 menit.

\section{Pengakuan/Acknowledgements}

Ucapan terima kasih disampaikan kepada pihak-pihak berikut yang terlibat secara langsung atau tidak langsung dalam kegiatan ini. Diantaranya Fakultas Teknik Universitas Bengkulu selaku pemberi dana pada kegiatan hibah PPM Pengabdian Fakultas Teknik Universitas Tahun 2020 dan Pejabat Pemerintahan, Pengurus Takmir Mesjid Al Muttaqin dan semua warga di lingkungan Perumahan Permata Griya Asri Kelurahan Surabaya Kota Bengkulu.

\section{Daftar Referensi}

Briyartendra, E.I., Widayat, W. (2019). Pengaruh Ukuran Partikel Dan Tekanan Kompaksi Terhadap Karakteristik Briket Kayu Jati. Jurnal Inovasi Mesin, 1(2), 14-22.

Ilyas, A. (2016). Bubur Kertas Untuk Perekat Briket Serbuk Gergaji Sebagai Sumber Energi Alternatif. Jurnal Ilmiah SETRUM, 5(2), 67-70.

Indriawan, dkk. (2020). Pengaruh Perekat Tar terhadap Karakteristik Briket. J-Protection, 5(1),1-5.

Riadi, M. (2012). Metode Demonstrasi Dalam Belajar. KajianPustaka.com, http://www.kajianpustaka.com/2012/10/metode-demonstrasi-dalan- 
belajar.html.

Riyadi, dkk. (2016). Rancang Bangun Alat Cetak Briket Sebagai Energi Alternatif Di Kepulauan. Seminar Nasional Mesin dan Teknologi Kejuruan.

Santosa, S., Soemarno. (2014). Peningkatan Nilai Kalor Produk pada Produk Proses Bio-drying Sampah Organik. Indonesian Green Technology Journal, 3(1), 29-38.

Saputro. (2012). Karakterisasi Briket Dari Sampah Organik Di Lingkungan Kampus Unnes. SAINTEKNOL - Jurnal Sain dan Teknologi, 10(1), 23-29.

Septhiani, S. (2015). Peningkatan Mutu Briket dari Sampah Organik dengan Penambahan Minyak Jelantah dan Plastik High Density Polyethylene (HDPE). Jurnal Kimia VALENSI: Jurnal Penelitian dan Pengembangan Ilmu Kimia, 1(2),91-96.

Setiowati, R., Tirono, M. (2014). Pengaruh Variasi Tekanan Pengepresan Dan Komposisi Bahan Terhadap Sifat Fisis Briket Arang. Jurnal Neutrino, 7(1), 23-31.

Sikumbang, H. d. (2018). Simulasi Pembuatan Dan Pemanfaatan Briket Pada Listrik Kerakyatan. Jurnal PETIR, 11(1).

Wijaya, A.A., dkk. (2021). Karakteristik Briket Biomassa dari Variasi Bahan Baku Dan Persentase Perekat yang Berbeda . Jurnal Beta, 9(2). 